\title{
AULAS PRESENCIAIS EM TEMPOS DE PANDEMIA: RELATOS DE EXPERIÊNCIAS DE PROFESSORES DO NÍVEL SUPERIOR SOBRE AS AULAS REMOTAS
}

\author{
André Machado Barbosa \\ Mestre em Desenvolvimento local pelo Centro Universitário \\ Augusto da Motta (UNISUAM), RJ, Brasil \\ Professor da Universidade Estácio de Sá (UNESA) \\ Professor da Faculdade Internacional Signorelli, RJ, Brasil \\ andre.mb.adm@gmail.com \\ Marco Antônio Serra Viegas \\ Especialista em Educação e Inclusão pela Pontifícia Universidade Católica (PUC-RJ), RJ, Brasil \\ Professor da Rede Municipal de Mesquita, RJ, Brasil \\ srmarcoviegas@gmail.com \\ Regina Lucia Napolitano Felício Felix Batista \\ Mestre em Desenvolvimento local pelo Centro Universitário \\ Augusto da Motta (UNISUAM), RJ, Brasil \\ Professora da Universidade Estácio de Sá (UNESA) \\ reginafelicio01@gmail.com
}

\section{RESUMO}

Este estudo buscou analisar e apresentar os dados obtidos através de pesquisa por meio do método quali-quantitativo, os impactos identificados e relatados pelos profissionais de educação do ensino superior, do município do Rio de Janeiro e Região Metropolitana, mediante isolamento social, sobre suas experiências do novo modelo de aula proposto pelas instituições, denominado como aula remota. As IES foram fechadas por determinação Ministério da Educação e Cultura (MEC) através da portaria no 343 de 17 de março de 2020, e autoriza a substituição das aulas presenciais nas instituições de ensino do país, por aulas que favoreçam os meios e as tecnologias de informação e comunicação. Neste contexto, esta pesquisa volta-se a dar vozes aos educadores, na tentativa de compreender a visão deles sobre as dimensões do acesso ao ensino e às condições oferecidas pelas instituições, com a pretensão de obter respostas as implicações descritas no objetivo geral e específicos desse trabalho. Desse modo, apresentamos em relatos e discussões, a tabulação dos dados obtidos, utilizando a estatística descritiva das respostas para apresentá-las aos leitores. Nos utilizamos de gráficos, com fins a aprimorar e demonstrar a amplitude da pesquisa. E, por fim, nas considerações finais, além de relatar a ampla análise do estudo, deixamos reflexões para futuras pesquisas, a respeito da concussão da COVID-19 no âmbito educacional e cultural.

Palavras-chave: Capacitação. COVID- 19. Ensino Híbrido. Aprendizagem. 


\title{
PRESENTIAL LESSONS IN PANDEMIC TIMES: RELATIONSHIPS OF EXPERIENCES OF HIGHER LEVEL TEACHERS ON REMOTE LESSONS
}

\begin{abstract}
This study sought to analyze and present the data obtained through research using the qualitative and quantitative method, the impacts identified and reported by higher education professionals in the city of Rio de Janeiro and the Metropolitan Region, through social isolation, about their experiences of the new class model proposed by the institutions, called remote class. The HEls were closed by determination of the Ministry of Education and Culture (MEC) through Ordinance No. 343 of March 17, 2020, and authorizes the substitution of face-to-face classes at educational institutions in the country, with classes that favor the means and technologies of education. Information and communication. In this context, this research, returns to give voices to educators, in an attempt to understand their view on the dimensions of access to teaching and the conditions offered by the institutions, with the intention of obtaining answers to the implications described in the general objective and specific to that work. Thus, in reports and discussions, we present the tabulation of the data obtained, using the descriptive statistics of the responses to present them to the readers. We use graphics to improve and demonstrate the scope of the research. And finally, in the final remarks, in addition to reporting the broad analysis of the study, we leave reflections for future research, regarding the concussion of COVID-19 in the educational and cultural scope.
\end{abstract}

Keywords: Training. COVID- 19. Hybrid Teaching. Learning. 


\section{INTRODUÇÃO}

A pandemia do COVID-19, nos remete à reflexão do quanto é importante a relação interpessoal, pois a falta de contato físico, por muitos, pode ser considerada um impedimento para expressar sentimentos e uma comunicação assertiva. No entanto, em um mundo em que a tecnologia é a ferramenta que tanto ansiamos e necessitamos para a solução de problemas, seja de ordem profissional, sentimental e/ou familiar, esta, torna-se a única aliada. E a privação dessa liberdade, na maioria da sociedade poderá despertar a necessidade de se relacionar fisicamente, um com os outros, ou não, mas talvez apontar uma nova cultura mundial.

Como vivemos na sociedade do conhecimento, os holofotes estão voltados não só à saúde para a cura dos já infectados pelo vírus, mas, também, pela democratização do acesso ao ensino. Na preocupação de ser um fator essencial para ajudar na contínua e necessária busca do aprendizado, buscou-se formas de continuar o processo de ensino/aprendizagem. Assim, emerge o ensino híbrido ${ }^{1}$ (BACICH; TANZI NETO; TREVISANI, 2015, p. 13) como ferramenta, através das metodologias ativas, a propor um instrumento tecnológico antes por muitas organizações utilizados, apenas para reuniões no formato de vídeo conferência, o modelo conceituado de aula on-line ou remota². (ALMEIDA, 2003, p. 332).

Dentro desta perspectiva futurista, ainda não vivenciada no Brasil, o governo se depara com essa problemática, e busca soluções por meio de normatizações a possibilitar as instituições de ensino ofertar aulas aos estudantes do país. Claro, principalmente, as privadas, tendo em vista a quebra de contrato na relação de consumo, caso deixem de ofertar, aos alunos, o ensino. Assim, o modelo de aula remota, seguindo tendências similares à implantação já praticada do ensino à distância, mas sobre o aspecto de ser online, ou seja, aulas ao vivo em tempo real, passam a ser utilizadas em caráter emergencial.

Em virtude dos fatos relatados, houve a necessidade de normatização, a qual foi realizada pelo Ministério da Educação e Cultura (MEC) através da portaria no 343 de 17 de março de 2020, para permitir a substituição das aulas presenciais nas instituições de ensino do país, por aulas que favoreçam os meios e as tecnologias de informação e comunicação.

\footnotetext{
${ }^{1}$ Ensino híbrido é uma abordagem pedagógica que combina atividades presenciais e atividades realizadas por meio das tecnologias digitais de informação e comunicação (TDICs).

${ }^{2}$ Educação on-line é uma modalidade de educação a distância realizada via internet, cuja comunicação ocorre de forma sincrônicas ou assincrônicas.
} 
Segundo o MEC, a intenção é de não ser prejudicial ao andamento dos cursos. A portaria, inicialmente, vale por 30 dias, com possível prorrogação face às orientações dos Órgãos competentes como: Ministério da Saúde e as demais secretarias de saúde estaduais e municipais.

Nesse contexto, esta pesquisa volta-se a dar vozes aos educadores, na tentativa de compreender a visão destes sobre as dimensões do acesso ao ensino e às condições oferecidas pelas instituições. Ouvi-los sobre o necessário processo de capacitação para utilizarem essa ferramenta tecnológica, como buscar saber sobre suas experiências mediante a aplicabilidade do novo modelo de aula.

Tendo em vista, que a qualificação do trabalho do professor e a relação ensino aprendizagem já vinha sendo desenvolvida por muitas instituições de ensino, mas não nesse aspecto. Logo, na compreensão que as políticas públicas de educação são direitos preservados na Constituição Federal, em uma perspectiva na qual o direito compreende o acesso e a garantia da qualidade do ensino, se faz necessário capacitar os protagonistas dessa importante relação ensino-aprendizagem, independente da modalidade a que for disponibilizada.

Contudo, a não capacitação e/ou instrumentação destes profissionais, pode tornar a portaria no 343 um divisor de águas nas políticas educacionais, assim instituindo um sistema que altera a oferta da Educação na modalidade presencial em atendimento às necessidades dos conteúdos aplicados. Dadas as dimensões sem precedentes, esta pandemia tende a provocar inúmeras transformações positivas, ou não, na vida dos envolvidos nessa nova forma de lecionar.

Portanto, a proposta é ouvir esse importante profissional no intuito de obter informações que se transformem em conhecimento científico, a fim de contribuir para construção de uma sociedade igualitária e perene. Como, também, através destes dados coletados, embasar discussões não meramente de caráter técnico e operacional, mas também a saber e considerar os aspectos físicos e emocionais. Até porque, estes profissionais estão atravessando, em meio a essa pandemia, uma abrupta mudança no seu modelo adaptável de ensino e vida. 


\section{OBJETIVO GERAL}

Este trabalho tem como objetivo central ouvir e tabular as respostas dos profissionais de educação do ensino superior sobre suas experiências com o novo modelo de aula proposto pelas instituições de ensino.

\section{OBJETIVOS ESPECÍFICOS}

Obter informações sobre o seu processo de capacitação para utilizar a ferramenta proposta. Identificar a percepção do impacto do uso destas ferramentas tecnológicas disponibilizadas pelas organizações educacionais, se cumprem o objetivo proposto. Analisar se houve transtornos que impactassem sua vida pessoal, como alterações psicossomáticas. Verificar sobre a satisfação do profissional sobre o novo modelo de aula.

\section{METODOLOGIA}

Este trabalho tem como objetivo central ouvir e tabular as respostas dos profissionais de educação do ensino superior sobre suas experiências no novo modelo de aula proposto pelas instituições de ensino, bem como obter informações sobre o seu processo de capacitação para utilizar as ferramentas propostas. E, ainda, identificar a percepção do impacto do uso destas ferramentas tecnológicas disponibilizadas pelas organizações educacionais e se cumprem o objetivo proposto e, também, analisar se houve transtornos que impactassem sua vida pessoal, como alterações psicossomáticas e, por fim, verificar sobre a satisfação do profissional sobre o novo modelo de aula.

A metodologia desta pesquisa inicia-se por levantamentos de dados coletados a partir de referencial teórico, em literatura específica, e consultas a artigos científicos, selecionados por meio de busca em banco de dados do Scielo, Emerald Insight e Periódicos Capes. No segundo momento, realizar a coleta de informações dos protagonistas do objetivo geral apresentado, visto ser a melhor forma de averiguar, é perguntar para alguém que está utilizando o modelo de aula proposto pelas organizações. Assim como considerouse a questão de o estudo envolver um fator social inédito, por tais motivos ouvir esses 
indivíduos, por meio de questionários estruturados que foram processados em caráter exploratório, o que foi considerado imprescindível.

Em um terceiro momento, tabular os dados obtidos no estudo qualitativo e quantitativo, utilizando a estatística descritiva das respostas e apresentá-las, por meio de gráficos no campo, resultados e discussões deste artigo. Para tal método, determina-se a identificação de falhas, erros, vantagens, tendências e interesses, ou não, do público alvo, abrangendo uma faixa delimitada apenas dos profissionais da região sudeste do país, como amostra, os docentes de ensino superior do estado do Rio de Janeiro, sendo mais específico, a sua capital e região metropolitana, que lecionam nas instituições públicas/privadas.

\section{REFERENCIAL TEÓRICO}

\subsection{Capacitação}

Em um mundo onde a tecnologia está atrelada a praticamente todas as profissões, possuir conhecimentos relativos às ciências tecnológicas, no exercício profissional de educador tem se tornado essencial. Mas ainda há muitos questionamentos por parte de professores que demonstram ter limitações com ferramentas tecnológicas.

No momento em que os processos educativos sofrem grandes mudanças, como neste, vem à tona ainda mais essas indagações quanto a inabilidade das ferramentas tecnológicas. A dar sentido à discussão, Minozzo, Cunha e Spindola (2016, p. 2) contribuem ao informar quanto a utilização de metodologias diferenciadas do convencional, levando o professor a perceber que o processo de ensino e aprendizagem também sofre alterações. Por isso, a necessária capacitação. Pois ao sair da sala de aula física para a virtual, sem ser o habitual e milenar uso dos métodos tradicionais de ensino, se faz necessárias adaptações não instantâneas.

Sendo assim, recorremos a Tardif (2002, p. 175) pois destaca sobre rejeitar a ideia de que, para ensinar, precisamos apenas conhecer o conteúdo específico da disciplina, ou seja, da sua área de formação. Deste modo, na visão do autor, tal conhecimento é necessário, mas não o suficiente, e não garante a competência dos professores, fazendo jus, a necessária capacitação destes profissionais para o novo ambiente de ensino. Dentro deste aspecto, buscamos em Alves (2018, p. 27) evidenciar ainda mais a respeito do assunto: 


\begin{abstract}
Analisando esse contexto, pode imaginar um grande desafio para os docentes atuais em participarem de um processo de mudança tão grande, no qual de um lado, uma grande parcela dos alunos nasce e cresce em contato constante com o meio digital, através de seus tablets e smartphones por exemplo, e do outro lado, docentes que já se atentavam com suas diversas atividades, agora tendo que repensar novas possibilidades mediante a conjuntura das novas tecnologias. E não falamos apenas do esforço em conhecer o uso de um novo dispositivo, ou ambiente virtual, aplicativo etc., mas, sim, pensarmos em como colocar isso em prática e de maneira com que o processo de ensino aprendizagem alcance seus objetivos. (ALVES, 2018, p. 27).
\end{abstract}

Nas instituições de ensino superior privadas, esta mudança deu-se quase imediatamente ao surgimento da pandemia, sob as orientações de isolamento social e decretos de fechamento dos espaços educacionais. Levando pesquisadores a debruçarem-se sobre a ótica de compreender os impactos da abrupta mudança na relação ensinoaprendizado na percepção dos protagonistas do fato, 'os professores'.

A justificativa das instituições de ensino é a lógica de continuidade da prestação de serviço ao aluno, regido por contrato, como também o calendário letivo. Mas será ser possível fazer uma alteração imediata de um habitual modelo educacional sem uma correta capacitação de profissionais, e não causar impactos negativos? Esta incógnita, também é uma questão a se encontrar respostas conforme um dos objetivos específicos deste estudo.

O Censo da Educação Superior de 2018 (INSTITUTO NACIONAL DE ESTUDOS E PESQUISAS EDUCACIONAIS ANÍSIO TEIXEIRA, 2019) no Brasil informa que são 384.474 professores atuando na rede público/privada. Sendo que a média de idade está entre 40 a 50 anos, ou seja, fazem parte da Geração X que teve de aprender a lidar com a tecnologia após a década de 1980, segundo Moraes (2011, p. 20). Mas diante da transformação instantânea, mesmos os que possuem habilidades, necessitam ser capacitados para atuarem com as novas ferramentas utilizadas, a fim de não comprometer o nível de excelência no método de ensino/aprendizado.

Maxwell (2016, p. 55) destaca "Capacitar é semelhante a treinar". Como na questão abordada a respeito da necessária habilidade dos professores com as novas ferramentas, concerne nesta pesquisa a ação de treinar e, por isso, buscou-se a visão de Chiavenato (1999, p. 55) ao destacar que: "Treinamento é o processo educacional de curto prazo aplicado de maneira sistemática e organizada, através do qual as pessoas aprendem conhecimentos, atitudes e habilidades em função de objetivos definidos". 
De modo a atender às recomendações da Organização Mundial da Saúde (OMS) e Ministério da Saúde (MS), já destacada, as equipes pedagógicas, assim como os alunos, necessitaram de capacitações para o uso de plataformas digitais em substituição às aulas presenciais. Visto que Moraes (2011, p. 34) corrobora ao informar sobre treinar, ser um recurso essencial para o desempenho profissional, pois permite aprendizado amplo, desenvolvimento de habilidades e promove exponencialmente a diminuição de erros, como também amplia a capacidade de realizar múltiplas tarefas.

Ainda que seja momentânea a utilização das ferramentas propostas pelas instituições de ensino, as estimativas diante das experiências em outras regiões do mundo demonstram que o prazo se estenda, até porque, no Brasil, segundo Croda et al. (2020, p. 2) a doença mostrou um aumento no número de casos em 31 de março, com 5.933 casos notificados e 206 óbitos registrados no Brasil. Nos levando a acreditar que este prazo da quarentena se estenda, o que cabe o entendimento da capacitação ter por objetivo o bom desempenho dos colaboradores na execução das ferramentas propostas pelas instituições de ensino superior. Desta forma, buscamos em Camilo, Gomes e Fortim (2018, p. 60) porque destaca sobre a observação da homogeneidade em relação aos gaps ${ }^{3}$ e às necessidades apresentadas pelos treinados, que devem ser, na medida do possível, observadas.

No presente momento, esses profissionais estão a vivenciar novas experiências das suas atividades laborais, com um pouco mais de complexidade. Visto que requer operações mentais mais completas para excelência da prestação de serviço. Sendo assim, tanto professores como alunos podem, de certa forma, identificar e/ou apresentar algumas dificuldades em todo o processo.

Até porque, diante de tantas metodologias fundamentais para esse processo de aprendizado, são necessários muitos dispositivos habilitados, como equipamentos que suportem as instalações, e conexões da web, visando também a segurança de dados e informações, logo, se faz necessário entender melhor o estudo do ensino híbrido, para compreender a importância da capacitação.

\footnotetext{
3 Gap: Segundo dicionário eletrônico Houaiss da língua versão 3.0, significa quebra de continuidade,
} descompasso ou disparidade entre coisas. 


\title{
5.2 Ensino Híbrido
}

As expressões da atualidade são: ensino híbrido, metodologias ativas e ensino remoto para aprendizagem. Deste modo, momento oportuno para aplicar esses métodos em busca de melhoria da dinamização das aulas e quem sabe melhorar as práticas utilizadas no ensino tradicional. Dentro desta perspectiva, Moran (2015) contribuiu ao destacar:

\begin{abstract}
Híbrido significa misturado, mesclado, blended. A educação sempre foi misturada, híbrida, sempre combinou vários espaços, tempos, atividades, metodologias, públicos. Esse processo, agora, com mobilidade e conectividade, é muito mais perceptível, amplo e profundo: é um ecossistema mais aberto e criativo. (MORAN, 2015, p. 27).
\end{abstract}

$\mathrm{Na}$ busca por compreender o conceito de aulas remotas, a pesquisa bibliográfica se conduziu à definição da expressão ensino híbrido. Sendo assim, recorremos aos estudos da Associação Brasileira de Educação à Distância - ABED (2019) no qual encontrou-se em um Clipping (TOMELIN; BARROS, 2020) sobre o tema, o entendimento como um propósito de mudança significativa para caminhos pedagógicos. Bem como de uma organização didática para ensino aprendizado, reunindo o melhor dos dois mundos, ou seja, o presencial e a distância. Logo, mediante a necessidade do isolamento social, essa metodologia torna-se eficiente a considerar urgência na continuidade do processo educacional.

Importante destacar que com o método de Ensino a Distância (EAD) se diferencia do ensino híbrido em toda sua contextualização. Nesta lógica, ter a real noção entre o que significam esses métodos, recorreu-se ao Portal do Ministério da Educação que define ensino a distância, como sendo a modalidade educacional na qual alunos e professores estão separados, física ou temporalmente e, por isso, faz-se necessária a utilização de meios e tecnologias de informação e comunicação. (BRASIL, 2020).

Contudo, novas formas de transmitir o conhecimento e os conteúdos são ofertados nas diversas plataformas digitais online, na qual as aulas acontecem de forma remota através do modelo síncrono (em tempo real) ou assíncrono (não é em tempo real), pois há recursos que funcionam também como o modelo EAD, que é o da gravação e disponibilização da aula, caso o aluno, naquele momento, não possa assistir.

Cabendo destacar, que o recurso de gravar e disponibilizar o material, não se refere a tornar o método similar ao EAD, e sim, o de tentar potencializar a ferramenta. Até porque, a visão deste recurso, é o de proporcionar não só o acesso dos alunos que não 
acompanharam a aula de forma remota, mas também destes alunos poderem revisar a explicação do professor (a), e esclarecer possíveis dúvidas.

Estas abordagens alternam diferentes etapas na aprendizagem e ao professor (a) desenvolver outras possibilidades de apresentar os conteúdos e provocar nos alunos a assimilação do conhecimento. Neste contexto, Rodrigues (2015, p. 124) destaca sobre no modelo de ensino híbrido, a tecnologia viabilizar novos e distintos métodos de avaliação, como recursos diversos, sistemas de cooperação ou de registro individual de resultados, formas variadas de entrega e apresentação do conteúdo programático.

Tais ferramentas digitais como: Teams da Microsoft, ZOOM, Hangouts, Duo, entre outras, são softwares de teleconferência, antes muito utilizados para reuniões coorporativas. Neste momento, viabilizam esse processo educacional remoto, trazendo além da conexão, a percepção do quanto o mundo tecnológico tem a contribuir em todo método de ensino aprendizado, ao qual Fantin (2011, p. 28) ressalta sobre importância das tecnologias digitais para a sociedade, abrindo espaço para a reflexão sobre o papel que as mídias têm desempenhado na contemporaneidade, e na formação dos sujeitos, em destaque aqui, para os estudantes, futuros profissionais. Nesse aspecto, Filatro e Cavalcante (2019) contribuem na percepção de:

\footnotetext{
Estudantes e profissionais deixam o papel passivo e de meros receptores de informação, que Ihes foi atribuído por tantos séculos na educação tradicional, para assumir um papel ativo e de protagonistas da própria aprendizagem...como selecionamos a perspectiva mais adequada para a aplicação de metodologias ativas no contexto educacional em que atuamos? A resposta é o nível de autonomia que os estudantes possuem para aprender. (FILATRO; CAVALCANTI, 2019, p. 18-19).
}

Contudo, dado aos fatos já dispostos, considerando o necessário processo de capacitação, a destreza do profissional com a ferramenta tecnológica, para o novo modelo apresentado, relaciona a pesquisa para abordagem dos impactos da práxis na relação ensino/aprendizado.

\subsection{Aprendizagem}

A aprendizagem é um processo contínuo que ocorre durante toda a vida do sujeito, e se organiza de várias formas e como muitos teóricos da educação destacam em inúmeros conceitos. Podemos citar alguns, dentre eles Vigotsky (1989), ‘a aprendizagem passa por um 
processo de internalização de conceitos', Skinner (1972) 'o sujeito aprende quando produz modificações no ambiente'; Piaget (1996) 'aprendizagem se dá por assimilação', Freire (1997) 'aprendizagem se dá na realidade dos sujeitos, aprendem com suas vivências'.

A ação de ensinar contempla uma compreensão que alcança mais que o espaço físico, o de conhecimento do professor (a), e das atividades realizadas pelos alunos (as). No entanto, todos os envolvidos nesse processo, docentes, discentes, e as instituições de ensino, deparam-se em contextos globais que interferem na relação. No caso deste estudo, a nova metodologia proposta para continuidade da aprendizagem se sobressai.

Replicar conteúdos, experiências e/ou práticas a alguém contempla visões diversificadas, seja de mundo, ou planejamento de ações. O trabalho destinado ao docente como instrumento de qualidade nesta relação, requer um planejamento e comprometimento do profissional de educação. Consoante a este contexto, Mattar (2017, p. 16) no prefácio assinado pelo professor Doutor Alvino Moser ${ }^{4}$, ao explicar sobre a diferença das metodologias tradicionais e ativas em meio à ação do ensino/aprendizado, destaca:

[...] Nas tradicionais, o professor concentrava a prerrogativa de dispor os conteúdos aos alunos: textos, vídeos, filmes e outros meios. Nas metodologias ativas, é o aluno que procura o conteúdo, seja em livros, seja em materiais digitais disponíveis na internet [...] (MATTAR, 2017, p. 16).

As propostas em debate no atual momento são de educação à distância, aulas remotas, plataformas de ensino entre outras e são muitas que vem a mobilizar as instituições de ensino em todas as instâncias, mas principalmente as instituições de ensino superior. Suas propostas metodológicas de interação do professor com o aluno, nomeadas de chats, fóruns, salas de tarefas e uma infinidade de ferramentas disponíveis na qual os envolvidos não dominam sua utilização, o que nos traz ao embate se somos seres tecnológicos, porém, não dominamos tais tecnologias e suas metodologias. Desse modo, recorremos a Munhoz, nos trazendo a reflexões, quando cita:

As mudanças exigidas no perfil de um novo profissional são presentes e deixam muitos professores insones na procura de como ensinar em um mundo com tantas mudanças. Elas não param de acontecer a uma velocidade de que não permite que o acompanhamento seja generalista. (MUNHOZ, 2018, p. 34).

No entanto, estamos enfrentando mudanças em nossos hábitos mais comuns, que têm causado muitas discussões e divergências quanto ao isolamento social e a

\footnotetext{
${ }^{4}$ Professor do Programa de Mestrado em Educação e Novas Tecnologias no Centro Universitário Internacional Uninter.
} 
impossibilidade de frequentar espaços de socialização, como é o do ensino/aprendizagem. Por conseguinte, Vera, Zúñiga e Bernal $(2013$, p. 1) contribui ao destacar o fato de a virtualização da educação estar tomando atualmente um interesse geral importante, dada a dinâmica social e didática educacional que representam a este respeito uma consequência positiva da evolução tecnológica. No que concerne à maneira pela qual, de forma eficaz, as instituições de ensino buscaram alternativas para continuar a assistir os discentes, sem comprometer a qualidade do ensino.

A experiência de aprendizagem neste modelo remoto envolve as instituições de ensino, equipes pedagógicas, docentes e discentes, todos vivenciando algo novo e de forma repentina. Recorremos a Franco $(2015$, p. 603) pois, neste sentido, considera que as relações entre professor, aluno, currículo e escola são relações que impõem uma convivência, tensional e contraditória, entre o sujeito que aprende e o professor que se organiza e prepara as condições para ensinar. Umas das particularidades a serem atenuadas sobre esse aspecto, é justamente a importância do docente dentro desse cenário, ou seja, a sua percepção diante do processo de ser e/ou sentir-se capacitado para essa moderna ferramenta na sua prática profissional.

Todavia, é uma novidade que entra de maneira imposta como a solução de todos os problemas da educação na realidade mundial. Novas metodologias são trazidas a público, especialistas trazem seus métodos revolucionários para a resolução de problemas, mas esquecem do foco, o aluno e sua relação com o conhecimento. Entretanto, Santos (2015, p. 103) nos traz um contraponto ao informar sobre os alunos e o uso das tecnologias:

\begin{abstract}
Os alunos do século XXI, das chamadas geração $\mathrm{Y}$ ou $\mathrm{Z}$, aprendem por muitos canais de informação, utilizam várias ferramentas que dinamizam o aprendizado e querem poder instrumentalizar seu ensino com a tecnologia que já utilizam para se comunicar e relacionar com seus amigos. É uma geração que não só ouve, mas fala, critica e constrói. (SANTOS, 2015, p. 103).
\end{abstract}

Em razão da demanda que emerge da sociedade, novas práticas têm sido bemvindas, a considerar o relatório da OCDE $^{5}$ (ORGANISATION FOR ECONOMIC CO-OPERATION AND DEVELOPMENT, 2010) que sugere ainda repensar em novas e melhores práticas de ensino, destaca Mattar (2017) no prefácio do seu livro. No qual, também, informa sobre o mesmo relatório indicar, sobre o século $X X$, que o conceito de aprendizagem ter tido

\footnotetext{
${ }^{5}$ Organização para a Cooperação e Desenvolvimento Econômico, em inglês, Organisation for Economic Cooperation and Development (OECD).
} 
desenvolvimentos importantes, sendo, na atualidade, a concepção de socioconstrutivismo a mais dominante.

Nesse contexto, os protagonistas desta relação ensino aprendizado "docentes" deparam-se com esse turbilhão de demandas a serem atendidas, como: a capacitação para o domínio da nova ferramenta, aperfeiçoar e/ou rever seus planejamentos de aula, face à nova metodologia proposta pelas instituições. Cabendo ressaltar, dentre outros aspectos, que estes profissionais tiveram suas rotinas de vida, em muitos casos, totalmente alteradas, com isso, a seguir, estão os resultados a serem analisados e discutidos com intuito de responder aos objetivos, geral e específicos, deste estudo científico.

\section{RESULTADOS E DISCUSSÕES}

Considerando o objetivo do presente trabalho, passamos a destacar a análise dos dados resultantes da pesquisa, realizada no mês de abril/2020, com docentes do nível superior de ensino, atuantes em instituições públicas e privadas. Foram coletadas informações sobre as experiências vivenciadas por estes profissionais da educação, no início da crise pandêmica, com relação às suas percepções dos impactos em seu processo de ensino aprendizado com os discentes.

Deste modo, as respostas dos profissionais estão tabuladas de forma quantitativa, apresentadas em gráficos. A considerar, Bueno (2002, p. 50) destaca que as necessidades humanas seguem padrões referentes ao modelo apropriado para a pesquisa.

Nessa perspectiva, inserimos nos questionários perguntas relacionadas à formação profissional, capacidade e conhecimento das ferramentas tecnológicas utilizadas, satisfação profissional com o atual momento vivenciado na educação (aulas remotas), houve treinamento para o uso de tais ferramentas. Segundo Hora, Monteiro e Arica (2010, p. 85), o questionário é uma das formas mais práticas de obtenção de informações quando existe a necessidade de saber sobre comportamentos, atitudes, opiniões e preferências, sendo utilizado como base de dados às pesquisas.

Foram entrevistados, 62 profissionais em educação, dentre $52,3 \%$ são do sexo masculino e $46,8 \%$ do feminino, sendo $52,5 \%$ do percentual com titulação de mestre, $18 \%$ doutoramento, 14,8 pós-doutorado, e 14,8 são especialistas. Na amostra, $82,3 \%$ lecionam em instituições privadas e $32,3 \%$ em públicas. Dos quais, $53 \%$ lecionam no curso de 
graduação, 27\% atuando na especialização, 11\% em cursos de mestrado, 5\% em doutorado, e $4 \%$ do total lecionam em cursos de capacitação. Cabendo destacar o fato dentre essa amostra, de haver profissionais que atuem em mais de um seguimento.

Ao serem questionados sobre utilizar metodologias ativas em suas aulas, $85,5 \%$ informaram aplicar. Quanto a conhecer o conceito de ensino híbrido, 88,7\% afirmam que conhecem. E sobre a definição de aulas de acesso remoto, $87,1 \%$ responderam saber.

Trazendo a reflexão quanto a metodologias ativas, como os conceitos abordados serem conhecidos e aplicados por um percentual considerável da amostra apresentada, os quais podem ser observados nos gráficos a seguir.

Gráfico 1: Uso de metodologias ativas nas aulas presenciais.
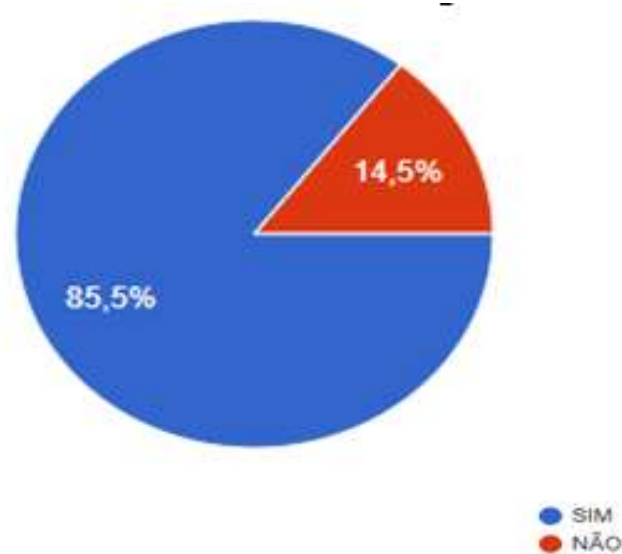

Fonte: Autores, 2020.

Gráfico 2: Conhecer o conceito de ensino híbrido.

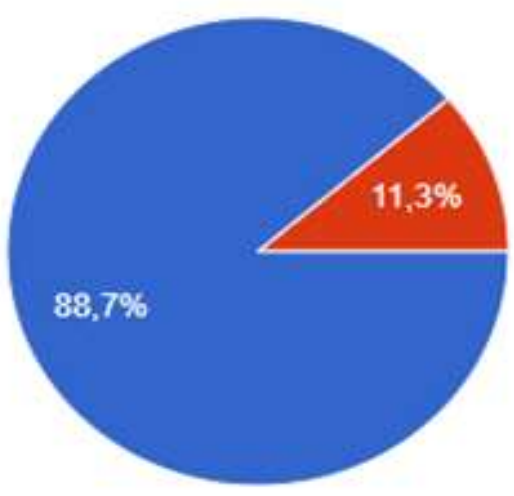


Gráfico 3: Conhecer o conceito de aulas com acesso remoto.
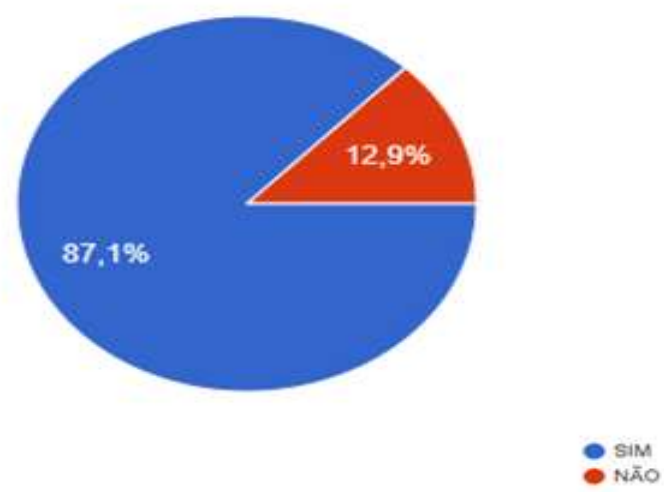

Fonte: Autores, 2020.

Gráfico 4: Possuir recursos para ministrar aulas com acesso remoto.

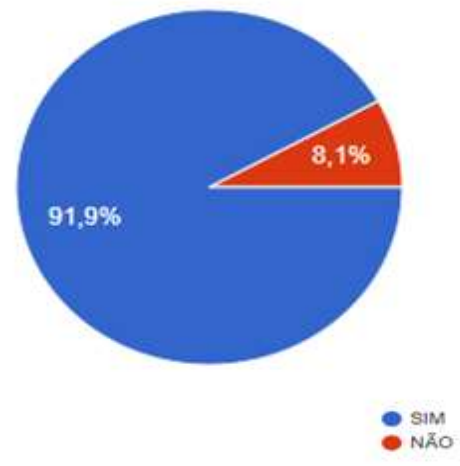

Fonte: Autores, 2020.

Dando sentido ao que Lara et al. (2019, p. 2) debatem sobre o papel dos profissionais da educação do ensino superior, diante de diversos desafios, estimularem a prática de ensino com base em metodologias ativas de ensino-aprendizagem. Dessa forma, assumem um destaque estratégico, o qual representa um fator crítico no desenvolvimento de iniciativas educacionais, cabendo destacar:

Apesar do pouco investimento na formação pedagógica dos docentes frente aos novos requerimentos dessa função, o papel do educador vem se transformando ao longo dos anos, particularmente no sentido de buscar um maior diálogo com novas demandas emergentes nas sociedades pós-modernas. (LARA, et al. 2019, p. 2).

Quanto a possuírem recursos para ministrarem as aulas em acesso remoto, 91,9\% dos profissionais afirmam tê-los. Mas ao serem perguntados se receberam algum incentivo 
financeiro das instituições as quais lecionam, a resposta de $79 \%$ foi negativa, ou seja, não receberam. Cabendo destaque, o fato da portaria № 343 de 17 de março de 2020, em seu artigo 1ำ, autorizar em caráter excepcional a substituição das aulas presenciais por meio de tecnologias, mas não promulgar em seu texto o mínimo de apoio financeiro aos profissionais de educação. No entanto, $11,3 \%$ dos respondentes afirmam ter recebido apoio monetário de seus provedores, para melhorar suas ferramentas tecnológicas ao uso no trabalho pedagógico. Entretanto, 9,7\% dos docentes, informaram que as instituições de ensino estão fechadas, com as aulas suspensas, a considerar em sua maioria, que essas instituições, são das universidades e institutos de ensino público.

Gráfico 5: Receber incentivo financeiro da instituição para adquirir ou melhorar os recursos para ministrar aulas com acesso remoto.

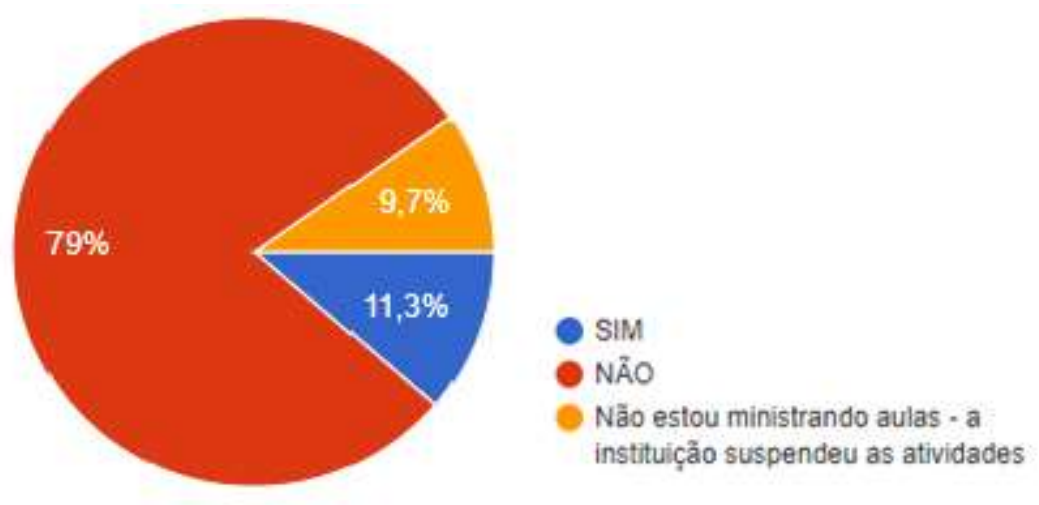

Fonte: Autores, 2020.

Apenas 58,1\% dizem ter experiência em ministrar aula com acesso remoto, logo, cabe destacar, sobre o fato de haver uma disparidade de $29 \%$ entre os que conhecem o conceito, ou metodologia, mas não possuírem habilidades. Ao qual reforça a necessária capacitação ou treinamento, conforme Chiavenato (1999, p. 55) como também Moraes (2011, p. 34), pois falam a respeito da necessidade de se treinar equipes, como um processo educacional de curto prazo, do qual contribui para aprimorar conhecimentos e desenvolver habilidades. Haja vista, a considerar o gráfico 5 e observar a disparidade, que nos levou a seguinte equação: $(87,1 \%-58,1 \%)+12,9 \%$, nos trazendo a análise do resultado, $41,9 \%$ sequer sabia utilizar. 
Gráfico 6: Ter experiência em ministrar aulas com acesso remoto.
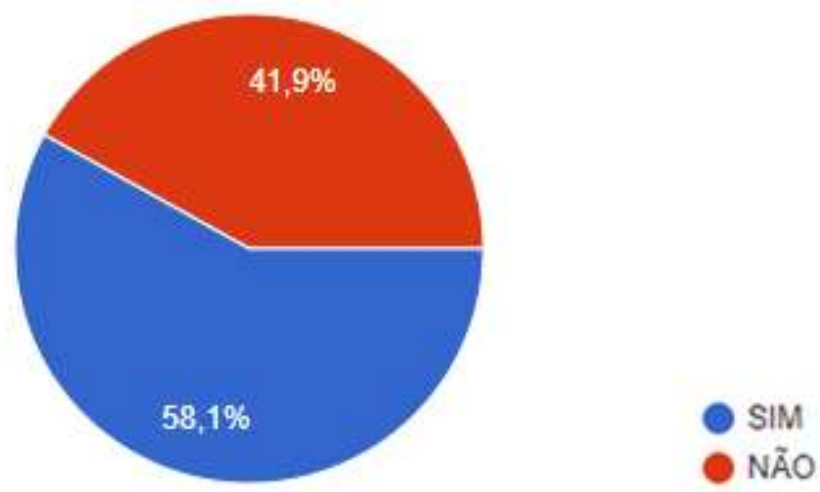

Fonte: Autores, 2020.

Quanto a capacitações, a pesquisa demonstra que as Instituições de Ensino Superior- IES capacitaram 50\% dos docentes, explicando-os da diferença de aulas com acesso remoto e EAD. Assim como, 67,7\% receberam o devido treinamento pelas instituições, a fim de capacitá-los ao uso da ferramenta escolhida para aulas com acesso remoto acontecerem. Mas houve um percentual considerado expressivo de $37,7 \%$ que não foram não informados da diferença entre aula de acesso remoto e EAD, da mesma maneira $21 \%$ não recebeu a essencial capacitação para utilizar o software determinado pela instituição de ensino.

Tal fato, considerado lastimável, porque segundo Meira e Quaresma Júnior (2018, p. 3) o uso adequado das novas tecnologias pode possibilitar que o ensino em sala de aula seja construído por meio de uma interação entre professor e aluno. Como também Maxwell (2016, p. 55), já destacado no referencial teórico deste estudo, informa, sobre capacitar e treinar, logo, tratando-se de metodologia e ferramenta nova, torna-se imprescindível ao docente.

Bem como a respeito da diferença entre a modalidade de ensino e a devida capacitação, $11,3 \%$ correspondem aos docentes que não estão lecionando, porque as instituições estão fechadas, a ser observado nos gráficos a seguir: 
Gráficos 7 e 8: Capacitação das IES sobre a diferença entre Acesso remoto e EAD. Capacitação pelas IES da ferramenta escolhida para utilização nas aulas remotas.
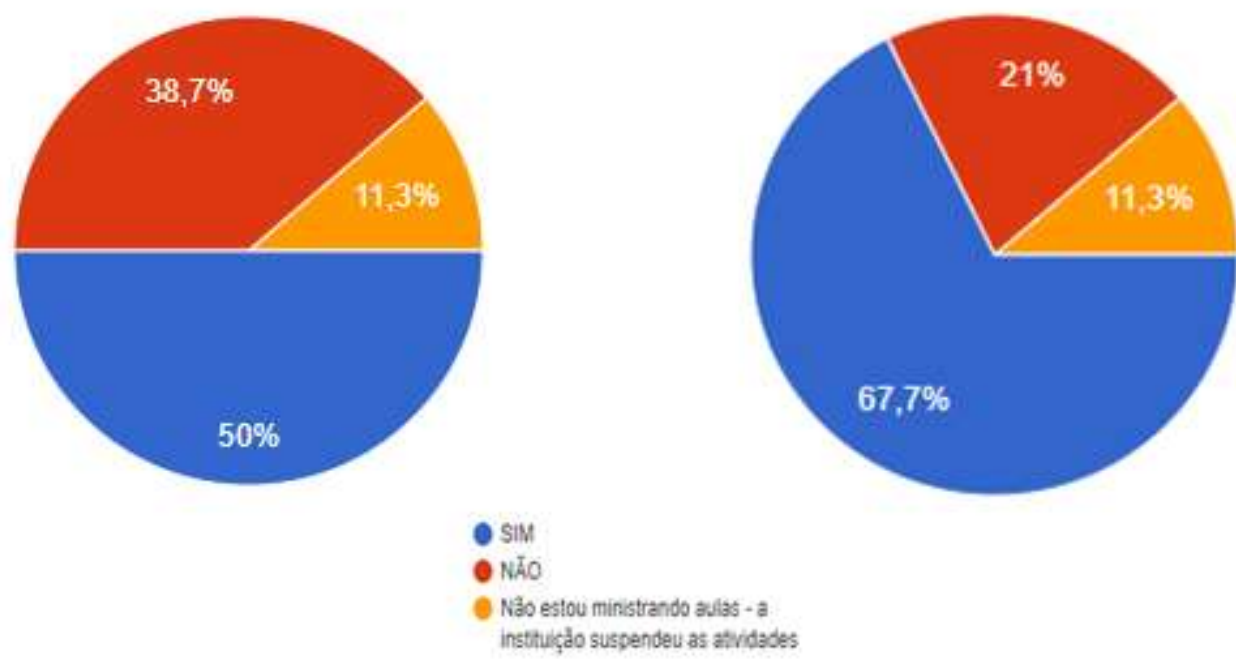

Fonte: Autores, 2020.

O percentual de respondentes a respeito das aulas pelo acesso remoto ocorrerem no mesmo tempo de duração das aulas presenciais foi de 50\%, e quanto à redução do tempo de aula pela metade, 38,7 afirmam ter havido redução. Tal como um número inexpressivo não está aplicando aula, mas está enviando materiais aos alunos por e-mail, e 9,7\% respondeu não estar lecionando, porque as instituições para que trabalham estão fechadas.

Gráfico 9: Tempo de duração da aula no acesso remoto serm diferente da aula presencial.

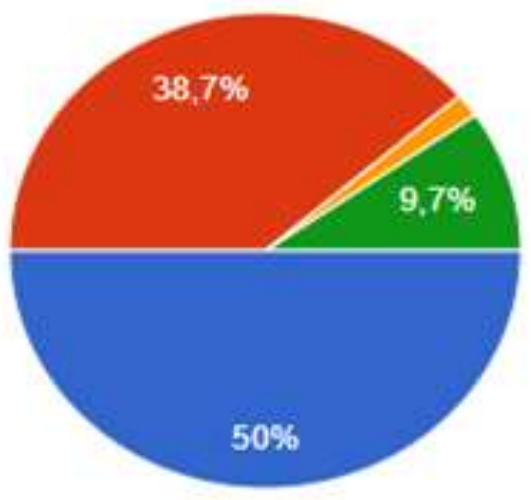

TEMPo TOTAL

$50 \%$ DO TEMPO

Não estou ministrando aulas com acesso remoto - utilizo e-mail para enviar material

Não estou ministrando aulas - a instituiçäo suspendeu as atividades

Fonte: Autores, 2020.

Nas respostas dos entrevistados, quanto à frequência dos alunos e aumento nas horas de trabalho, foi constatada uma dicotomia nos resultados apurados, menor 
participação dos alunos quanto às aulas presenciais, e maior carga de trabalho referente à preparação dos materiais para as aulas remotas. Encontra-se uma relação percentual bem próxima de 59\%, o que nos faz refletir quanto aos benefícios propostos aos alunos, por esta forma de ensino e as novas práticas do professor, conforme Alves $(2018$, p. 7$)$ nos fala sobre o posicionamento de docentes imersos nesse mundo digital e com dificuldade em usar os meios tecnológicos para atender melhor suas alunos, que fazem uso habitual desses recursos.

Gráfico 10: Frequência dos alunos nas aulas remotas.

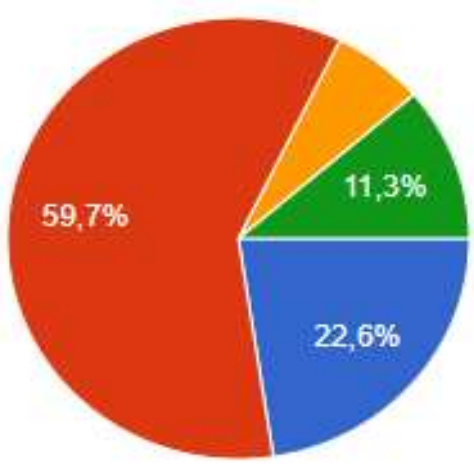

igual na aula presencial

menos que na aula presencial

mais que na aula presencial

Não estou ministrando aulas - a

instituição suspendeu as atividades

Fonte: Autores, 2020.

Gráfico 11: Proporção de aumento de horas trabalhadas no preparo de materiais para aulas remotas.
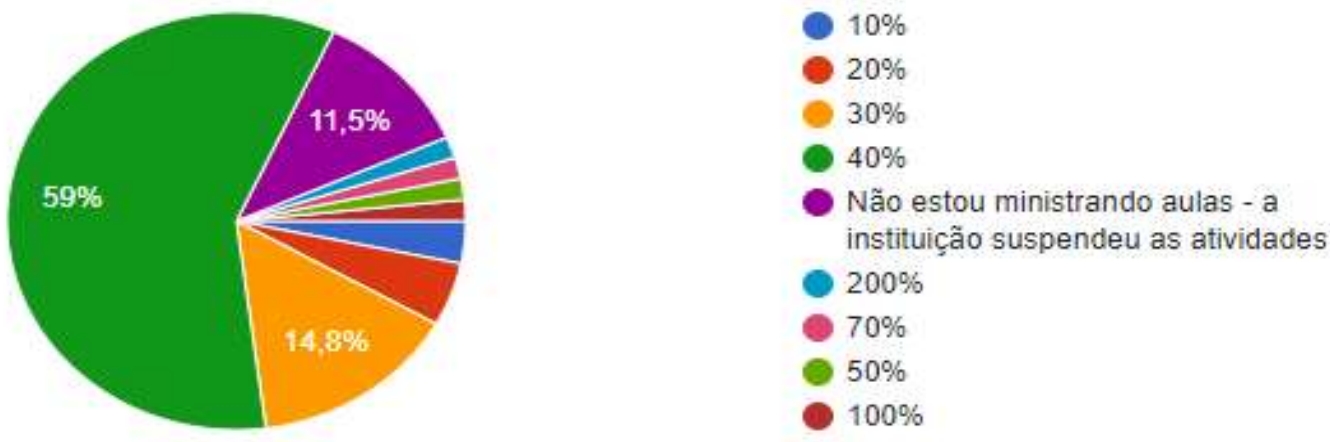

Fonte: Autores, 2020.

Foram apresentadas aos docentes, nesta pesquisa, várias ferramentas e plataformas digitais, as quais estão sendo disponibilizadas pelas instituições de ensino, e plataformas próprias de uso das organizações. Dentre as ferramentas mais usadas, a Zoom e a Teams da Microsoft como sendo as mais utilizadas, consideradas de boa repercussão pela praticidade e facilidade do trabalho e acesso. Logo, sobre esta análise dos dados, Chiavenato 
(2000, p. 395) coloca "Quanto mais poderosa a tecnologia de informação, tanto mais informado e poderoso se torna o usuário" o que nos faz a compreender as escolhas.

Buscou-se apurar o número médio de alunos nas salas presenciais, recursos que estão utilizando para acesso às aulas remotas, e saber das dificuldades encontradas pelos discentes para assistirem suas aulas. Segundo os docentes, em sua maior parte, as turmas presenciais possuem a média entre 26 e 40 alunos, e informaram que a presença nas salas virtuais é menor que nas presenciais. Mas, quanto aos recursos utilizados pelos alunos para acessarem as aulas, $49,9 \%$ disseram ser, celular o mais utilizado, e dentre as dificuldades apresentadas para assistirem as aulas, 33,9\% atrelaram ao acesso a rede de internet.

Gráfico 11: Média de Alunos por turma.

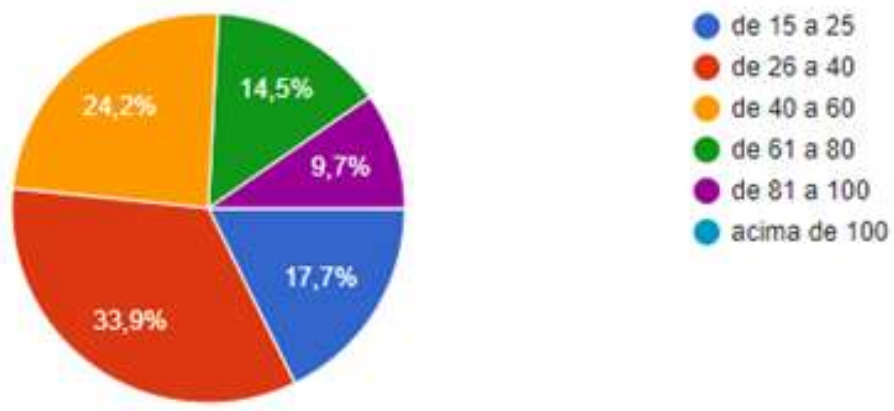

Fonte: Autores, 2020.

Gráfico 12: Recursos utilizados pelos alunos para assistirem as aulas.

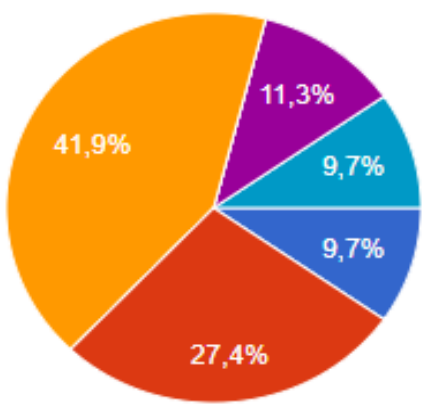

COMPUTADOR - DESKTOP

COMPUTADOR - NOTEBOOK

CELULAR

TABLET

NÃO TENHO ESTA INFORMAÇÃO

ALUNOS COM AULAS SUSPENSAS

Fonte: Autores, 2020. 
Gráfico 13: As dificuldades dos alunos para assistirem as aulas remotas.

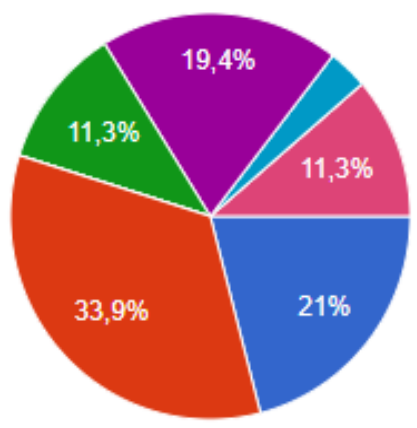

SIM - não tem computador ou outro equipamento

SIM - a internet não atende

SIM - não tem recursos de câmera

SIM - não tem recurso de áudio

Não reclamam

NÃO TENHO ESTA INFORMAÇÃO

ALUNOS COM AULAS SUSPENSAS

Fonte: Autores, 2020.

O conceito de aulas remotas demonstrou ser confundido com EAD, na visão dos alunos, que não conseguem entender a diferença entre as duas modalidades, fato este em que uma relevante parte dos docentes nos relata. Moran (2015, p. 30) apresenta que "aprendemos mais e melhor quando encontramos significado para aquilo que percebemos", podemos externar que sem os conceitos definidos e trabalhados com os discentes, não haverá entendimento da diferença entre eles. No entanto, muitos não possuem os recursos próprios para o acompanhamento das aulas e segundo o estudo, em sua grande maioria, apontaram que nenhuma ação foi realizada para que o discente não se sinta excluído.

Gráfico 14: Alunos sabem a diferença entre aula remota e EAD.

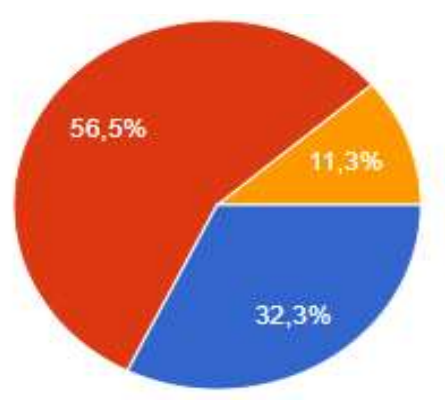

Fonte: Autores, 2020. 
Gráfico 15: Houve ação inclusiva para alunos que não possuem recursos para assistirem as aulas nesse novo modelo.

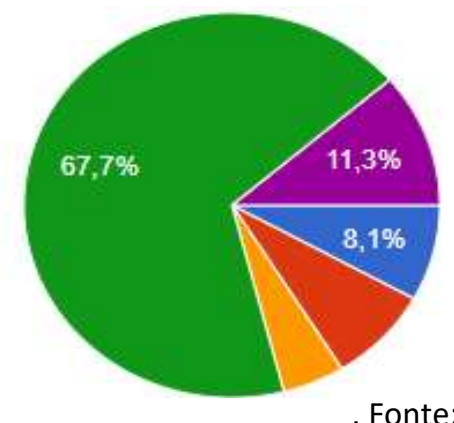

SIM - fizemos doações de

equipamentos e pacote de dados

SIM - pacote de dados

SIM - equipamentos

NÃO

- alunos com aulas suspensas

. Fonte: Elaborado pelos autores, 2020.

A análise dos dados apresentados, a considerar o embasamento teórico e a metodologia utilizada, pôde demonstrar que as respostas relatam que instituições de ensino superior estão garantindo que os professores transmitam o conhecimento esperado e que os alunos desenvolvam as tarefas solicitadas de forma remota. Mas, devido alguns números expressivos apresentados e podendo ser comprovados através dos gráficos expostos, podemos afirmar que, com a mesma qualidade das aulas presenciais, torna-se dicotômico. Cabendo a compreensão de tais fatores, ocorrem dadas condições sociais e financeiras de uma grande parte dos alunos, demonstradas pelas dificuldades de acesso pelos motivos constatados e que possam dar-Ihes uma sensação de exclusão.

\section{CONSIDERAÇÕES FINAIS}

No presente trabalho, buscou-se apresentar uma discussão entre a educação presencial e sua adaptação à educação online, com aulas de acesso remoto na educação superior a viabilizar ao aluno a continuidade do ensino e suas implicações no processo de aprendizado e atuação do docente no uso das ferramentas digitais, a considerar os impactos positivos e negativos nessa adaptação pedagógica e uma possível dificuldade na utilização dos dispositivos tecnológicos para o acompanhamento às aulas sincrônicas.

Não obstante à situação dos alunos, apresentada nos resultados e discussões, de possivelmente se sentirem excluídos, cabe o olhar atento aos profissionais de ensino, que também podem ter o mesmo sentimento. Até porque, um percentual significativo, informaram saber apenas o conceito de ensino híbrido, mas não possuir habilidade com a ferramenta. Assim, como a uma parcela expressiva dentro da amostra, não foi dado se quer 
um treinamento básico e entendimento das diferenças entre as modalidades de ensino, através da ferramenta tecnológica.

Cabendo considerações ao fato de que, para se obter uma boa relação entre tecnologia e usuário, é preciso que haja o mínimo necessário de treinamento. E mesmo àqueles que de algum modo já possuíam habilidades com as Tecnologias da Informação e Comunicação (TICs), os professores que lecionam, presencialmente, não utilizavam essa ferramenta proposta pelas IES.

A solução, visto aos dados apresentados pela pesquisa, demonstrou ser eficiente, o modelo de aulas remotas, porque houve uma boa realização das tarefas e atividades conforme o planejado. Porém, não eficaz, a considerar que não houve uma totalidade de alunos com acesso ao ensino/aprendizagem, fator que compromete a qualidade da prestação de serviço das IES públicas e privadas.

Relevante informar que os softwares apresentados para o modelo de aula, proposto pela IES, são modelos adaptados. Essas ferramentas são meios de interação que atendem a modelos coorporativos, com objetivo de conectar os colaboradores, e melhorar a interação das equipes, fornecendo uma alternativa de comunicações, e até mesmo substituição do uso de e-mail. Ao olhar dos pesquisadores, muito bem adaptados, porque permite ao aluno, um contato com a realidade do ambiente profissional coorporativo.

Considerar, também, que nesse processo ensino/aprendizado, o profissional de educação, pode ser acometido por uma outra problemática, talvez desconhecida, que seja, a frustação do não conhecimento e domínio pleno da ferramenta, ampliando sua cargahorária de trabalho em busca dessa competência. Cabendo, ainda, mais atenção, pois tudo isso, passando pelo processo pandêmico, de total isolamento social, requer de equilíbrio emocional e boas práticas para manter, também, uma saúde física, mental e financeira.

\section{REFERÊNCIAS}

ALMEIDA, Maria Elizabeth Bianconcini de. Educação a distância na internet: abordagens e contribuições dos ambientes digitais de aprendizagem. Educação e Pesquisa, São Paulo, v. 29, n. 2, p. 327-340, 2003. Disponível em: http://www.scielo.br/pdf/ep/v29n2/a10v29n2.pdf. Acesso em: 23 abr. 2020.

ALVES, Leonardo Meireles. Gamificação na educação: aplicando metodologias de jogos no ambiente educacional. Joinvile: Clube dos Autores, 2018. 
BACICH, Lilian. TANZI NETO, Adolfo. TREVISANI, Fernando de Mello. Ensino híbrido: personalização e tecnologia na educação. Porto Alegre: Penso, 2015.

BRASIL. Ministério da Educação. O que é educação a distância? Brasília, DF: Ministério da Educação, 2020. Disponível em: http://portal.mec.gov.br/escola-de-gestores-da-educacaobasica/355-perguntas-frequentes-911936531/educacao-a-distancia-1651636927/12823-oque-e-educacao-a-distancia.pdf. Acesso em: 23 abr. 2020.

BUENO, Marcos. Programas de qualidade no setor avícola brasileiro: o caso da granja planalto. 2002. 197f. Dissertação (Mestrado em Engenharia de Produção) - Programa de Pós-Graduação em Engenharia de Produção, Universidade Federal de Santa Catarina, Florianópolis, 2002.

CAMILO, Juliana; GOMES, Dione Fagundes Nunes; FORTIM, Ivelise. (org.). Gestão de pessoas: práticas em treinamento e desenvolvimento. São Paulo: Ed. SENAC São Paulo, 2018.

CHIAVENATO, Idalberto. Gestão de pessoas: o novo papel dos recursos humanos nas organizações. Rio de Janeiro: Campus, 1999.

CHIAVENATO, Idalberto. Introdução a teoria geral da administração. 2. ed. Rio de Janeiro: Campus, 2000.

CRODA, Julio; OLIVEIRA, Wanderson Kleber de; FRUTUOSO, Rodrigo Lins; MANDETTA, Luiz Henrique; SILVA, Djane Clarys Baia da; SOUSA, José Diego Brito; MONTEIRO, Wuelton Marcelo; LACERDA, Marcus Vinícius Guimarães. COVID-19 in Brazil: advantages of a socialized unified health system and preparation to contain cases. Revista da Sociedade Brasileira de Medicina Tropical, [S. I.], v. 53, 2020. Disponível em: https://preprints.scielo.org/index.php/scielo/preprint/view/7/14. Acesso em: 23 abr. 2020.

FANTIN, Mônica. Mídia-educação: aspectos históricos e teórico-metodológicos. Olhar de professor, Ponta Grossa, v. 14, n. 1, p. 27-40, 2011. Disponível em: https://www.revistas2.uepg.br/index.php/olhardeprofessor/article/view/3483. Acesso em: 23 abr. 2020.

FILATRO, Andrea; CAVALCANTI, Carolina Costa. Metodologias inovativas na educação presencial, à distância e corporativa. São Paulo: Saraiva, 2019.

FRANCO, Maria Amélia Santoro. Práticas pedagógicas de ensinar-aprender: por entre resistências e resignações. Educ. Pesquisa, São Paulo, v. 41, n. 3, p. 601-614, 2015. Disponível em: http://www.scielo.br/pdf/ep/v41n3/1517-9702-ep-41-3-0601.pdf. Acesso em: 25 abr. 2020.

FREIRE, P. Pedagogia da autonomia: saberes necessários à prática educativa. São Paulo: Paz e Terra, 1997.

HORA, H. R. M.; MONTEIRO, G. T. R.; ARICA, J. Confiabilidade em questionários para qualidade: um estudo com o coeficiente alfa de cronbach. Produto \& Produção, [S. I.], v. 11, 
n. 2, p. 85-103, 2010. Disponível em:

https://seer.ufrgs.br/ProdutoProducao/article/view/9321/8252. Acesso em: 25 abr. 2020.

INSTITUTO NACIONAL DE ESTUDOS E PESQUISAS EDUCACIONAIS ANÍSIO TEIXEIRA. Censo da educação superior 2018: notas estatísticas. Brasília, DF: INEP/MEC, 2019. Disponível em: http://download.inep.gov.br/educacao_superior/censo_superior/documentos/2019/censo_ da_educacao_superior_2018-notas_estatisticas.pdf. Acesso em: 19 abr. 2020.

LARA, Ellys Marina de Oliveira; LIMA, Valéria Vernaschi; MENDES, Juliana Delalibera; RIBEIRO, Eliana Claudia Otero; PADILHA, Roberto de Queiroz. O professor nas metodologias ativas e as nuances entre ensinar e aprender: desafios e possibilidades. Interface (Botucatu), Botucatu, v. 23, n. e180393, p. 1-15, 2019. Disponível em:

https://www.scielo.br/pdf/icse/v23/1807-5762-icse-23-e180393.pdf. Acesso em: 25 abr. 2020.

MATTAR, João. Metodologias ativas: para a educação presencial, blended e a distância. São Paulo: Artesanato Educacional, 2017.

MAXWELL, John C. Segredos da capacitação. Tradução: Valéria Lamim Delgado Fernandes e Jorge Camargo. Rio de Janeiro: Vida Melhor, 2016.

MEIRA, Ana Clara Gonçalves Alves de; QUARESMA JÚNIOR, Edson Antunes. Uma proposta de capacitação docente ao uso das novas tecnologias no ensino em uma escola da rede pública de Salinas-MG. Revista Tecnologias na Educação, [S. I.], ano 10, v. 25, 2018. Disponível em: http://tecedu.pro.br/wp-content/uploads/2018/07/Art49-vol.25-Junho-2018.pdf. Acesso em: 26 abr. 2020.

MINOZZO, Luís César; CUNHA, Gladis Franck da; SPINDOLA, Marilda Machado. A importância da capacitação para o uso de tecnologias da informação na prática pedagógica de professores de ciências. Revista Interdisciplinar da Ciência Aplicada, [S. I.], v. 1, n. 1, 2016. Disponível em: http://www.ucs.br/etc/revistas/index.php/ricaucs/article/view/4306. Acesso em: 26 abr. 2020.

MORAES, Márcia Vilma Gonçalves de. Treinamento e desenvolvimento: educação corporativa: para as áreas de saúde, segurança do trabalho e recursos humanos. São Paulo: Érica, 2011.

MORAN, José. Um conceito-chave para a educação, hoje. In: BACICH, Lilian. TANZI NETO, Adolfo. TREVISANI, Fernando de Mello. Ensino híbrido: personalização e tecnologia na educação. Porto Alegre: Penso, 2015. p. 27-45.

MUNHOZ, Antônio Siemsen. Aprendizagem baseada em problemas. São Paulo: CENGAGE, 2018.

ORGANISATION FOR ECONOMIC CO-OPERATION AND DEVELOPMENT. Development cooperation report 2010. [Paris]: OECD, 2010. Disponível em: https://www.oecdilibrary.org/development/development-co-operation-report-2010_dcr-2010-en. Acesso em: 23 abr. 2020. 
PIAGET, J. Biologia e conhecimento. Petrópolis: Vozes, 1996.

RODRIGUES, Eric Freitas. A avaliação e a tecnologia. In: BACICH, Lilian. TANZI NETO, Adolfo. TREVISANI, Fernando de Mello. Ensino híbrido: personalização e tecnologia na educação. Porto Alegre: Penso, 2015. p. 123-137.

SANTOS, Glauco de Souza. Espaços de aprendizagem. In: BACICH, Lilian. TANZI NETO, Adolfo. TREVISANI, Fernando de Mello. Ensino híbrido: personalização e tecnologia na educação. Porto Alegre: Penso, 2015. p. 103-120.

SKINNER, B. F. Tecnologia do ensino. São Paulo: Ed. Herder: Ed. da USP, 1972.

TARDIF, Maurice. Saberes docentes e formação profissional. Petrópolis: Vozes, 2002.

TOMELIN, Janes Fidélis; BARROS, Sylvia de Moraes. Dica: ensino híbrido. Direcional Escolas, [S. I.], 2020. Disponível em:

http://www.abed.org.br/arquivos/rev_direcional_escolas_pg_24.pdf. Acesso em: 23 abr. 2020.

VERA, Alexander; ZÚÑIGA, Nathan; BERNAL, Álvaro. Herramienta en línea para la programación y depuración remota de funciones lógicas digitales. Ingeniería y Competitividad, [S. I.], v. 15, n. 1, p. 79-91, 2013. Disponível em: http://www.scielo.org.co/pdf/inco/v15n1/v15n1a08.pdf. Acesso em: 23 abr. 2020.

VIGOTSKY, L. S. Pensamento e linguagem. São Paulo: Martins Fontes, 1989.

Recebido em 28/04/2020

Aceito em 11/05/2020 